\title{
QUANDO COMPARAMOS PARA EXPLICAR Desenhos de pesquisa e sequências temporais na investigação de instituições políticas
}

\section{André Marenco dos Santos}

Por que comparar? Todo comparatista possui uma resposta-padrão para esta interrogação: diante da impossibilidade de recorrer a métodos experimentais que permitam o isolamento de variáveis e a repetição de testes, compara-se como recurso para identificar regularidades, baseando-se no cânone milliano, no método das semelhanças e das diferenças ou na observação de variaçôes concomitantes.

Mais do que descrever singularidades, o que talvez defina uma abordagem característica da ciência seja sua tentativa de descobrir regularidades, padrôes comuns presentes em fenômenos distintos. A partir disso, procura-se responder como variaçōes em alguns fatores provocam consequências sobre outros. Democracias são o resultado de complexas combinaçôes institucionais, a tal ponto que provavelmente não encontraremos dois casos de sistemas

Artigo recebido em 16/01/2012

Aprovado em 22/05/2012 democráticos nacionais inteiramente iguais. Contudo, a despeito da heterogeneidade institucional, é possível recortar padrôes regulares, a exemplo dos modelos consociativo e majoritário, cunhados por Lijphart (1999). Da mesma forma, podem-se fazer inferências sobre os efeitos provocados por cada um destes arranjos institucionais em termos de desempenho democrático, tipo de políticas públicas etc. As leis de Duverger constituem exemplo bem-sucedido de regularidade causal, isolando o impacto de regras eleitorais de plurality com bi-partidarismo e voto estratégico.

Para além da retórica escolar, deve-se considerar a presença de distintas estratégias de investigação comparativa, informadas pelo escopo dos problemas analíticos, combinado à expectativa de resultados a que se pretende atingir com o recurso à comparação. Em outras palavras, isto diz respeito à controvérsia relativa ao uso da comparação como método para a formulação de explicaçôes 
causais, ou, em parcimonioso contraste, como estratégia de controle para a validade de interpretações generalizantes. Seguindo autores como Ragin (1987), Przeworski (1987) e Panebianco (1994), o método comparativo deve ser empregado como recurso para a construção de modelos explicativos causais de escopo generalizante. $\mathrm{O}$ uso adequado da investigação comparada, considerando o problema analítico, a consistência do modelo teórico, o recorte temporal, o número de casos e variáveis examinados, constitui condição para extrair explicações causais robustas. Em extremo oposto, podemos encontrar a escolha de Tilly (1991) por comparações individualizadoras ou a cautela metodológica de Sartori (1994) para quem a comparação presta-se, mais modestamente, para controlar a aplicação de generalizações a casos particulares, verificando ou falsificando hipóteses explicativas em circunstâncias diversas. Neste caso, compara-se para formular interpretações capazes de reconstituir casos específicos.

$\mathrm{O}$ argumento que guia este texto se baseia na ideia de que a vocação dos estudos comparados consiste na busca da construção de inferências causais generalizantes, aptas a explicar formação, estabilidade e mudança em instituições políticas. $\mathrm{Na}$ primeira seção, identificam-se impasses na teoria institucional, localizados na fragilidade de interpretações sobre a formação de instituições, bem como uma compreensão das condições nas quais instituições se mostram capazes de provocar os efeitos a elas atribuídos; na segunda, procura-se mostrar como a noção de comparação como estratégia investigativa baseada em poucos casos, muitas variáveis, fixada por Lijphart e a geração fundacional de política comparada (Moore, Tilly, Skocpol, Bendix), terminou por reduzir seu potencial para a construção de explicações generalizantes, limitando-a a um escopo de controle de hipóteses. Incremento e diversificação significativos no número de casos do objeto a ser explicado (poliarquias) implicariam em impossibilidade de construção de explicações generalizantes a partir de $\mathrm{N}$ pequeno. A terceira seção objetiva reforçar os argumentos em favor da incorporação de intervalos e sequências temporais à análise comparada.

\section{Afinal quais instituiçóes importam?}

O enigma recorrente que demarca a agenda das ciências sociais está em revelar os mecanismos que constituem as relaçôes de influência recíproca entre estruturas (instituições, organizações, grupos) e ações individuais. Trata-se de desvendar as condições que permitem a produção de equilíbrios sociais, caracterizados por circunstâncias nas quais nenhum agente possui incentivos para alterar estratégias ou curso de ação, desde que os demais também não o façam. Disso decorre o desafio em explicar a origem, a estabilidade e a mudança, bem como as variações observadas na configuração das instituições políticas: por que algumas nações possuem instituições democráticas e outras não? Por que certas democracias são estáveis, enquanto outras apresentam ciclos endêmicos de crise institucional? Quais fatores podem explicar as diferenças registradas em regimes poliárquicos, como relações Executivo-Legislativo, fórmula eleitoral, sistemas partidários, estrutura federativa, escolha por políticas keynesianas ou monetaristas?

De alguma forma, as principais escolas analíticas constituídas na ciência política internacional durante o último século - pluralismo, nos anos de 1930, behaviorismo, nos anos de 1950, sociologia política e individualismo metodológico, nas décadas de 1960 e 1970, neoinstitucionalismo(s), dos anos de 1990 em diante - procuraram construir inferências causais aptas a explicar como estruturas condicionam valores, comportamentos ou preferências dos agentes ou, inversamente, como estes e suas crenças modelam aquelas estruturas (Goodin, 2009). Paralelamente, foram confeccionadas as regras do jogo, ou seja, os termos legítimos para o debate científico e o que deve conferir plausibilidade às hipóteses construídas a partir de diferentes proposições analíticas, buscando a construção de modelos teóricos formais e explicaçôes causais empiricamente fundadas. Não dispondo de recurso à experimentação, disponível às ciências naturais, resta à investigação política o uso de comparação como procedimento para isolar regularidades e associações de causa e efeito. Desde Mill, tem sido usual o emprego de comparações pelo método das semelhanças e das diferen- 
ças, isolando fatores comuns capazes de explicar efeitos similares ou, em contraste, separando discrepâncias de características comuns, como estratégia para explicar a produção de consequências ou estruturas distintas (Pennings, Keman e Kleinnijenhuis, 2006; Boix e Stokes, 2007).

Como explicar a coexistência entre estratégias políticas maximizadoras por agentes políticos com a presença de equilíbrios sociais e estabilidade institucional? Paradoxos da escolha social conduzindo a elevados custos de transação e ausência de estabilidade institucional haviam sido descritos por Arrow (1951) em seu teorema da impossibilidade. Da mesma forma, para Riker (1962) o axioma do indivíduo racional deveria produzir equilíbrio social e institucional precários, traduzidos em inconsistência decisória e ciclos de maioria.

Em contraste com este diagnóstico, a literatura institucionalista a partir dos anos de 1980 destacou o papel das instituiçóes políticas como promotoras de um structure-induced equilibrium. $\mathrm{O}$ argumento institucionalista de que instituiçôes importam, na medida em que induzem preferências e escolhas, resolvem problemas de coordenação e selecionam resultados de políticas públicas, torna-se especialmente persuasivo quando amparado por casos exemplares de constrangimentos produzidos por procedimentos institucionais. A agenda de pesquisa construída em torno de consequências políticas das regras eleitorais provavelmente é a área em que a demonstração dos efeitos provocados por instituições políticas tenha apresentado evidências mais robustas. Desde a proposição original das Leis de Duverger sobre os fatores mecânicos e psicológicos produzidos pelas fórmulas de conversão de votos em cadeiras legislativas (Duverger, 1954, 1986), inúmeras evidências foram apresentadas, revelando o impacto gerado pelas regras sobre o formato da competição eleitoral: incentivos ao voto estratégico (Taagepera, 1984; Lijphart, 1990; Sartori, 1996; Cox, 1997), as consequências geradas pela magnitude eleitoral e mecanismos de alocação de sobras (Rae, 1967; Taagepera e Shugart, 1989), associando configuração institucional (plurality, magnitude eleitoral pequena [M pequeno]) com bipartidarismo.

Exemplos de condicionamentos institucionais sobre estratégias individuais podem ser encontra- dos, também, nas conexões entre estrutura institucional e políticas públicas (Weir e Skocpol, 1985; Rothstein e Steinmo, 2002), nos registros de Ostrom (1990, 1999), mostrando como instituições permitiram a resolução de problemas de coordenação individual no uso de recursos naturais e evitando a tragédia dos bens comuns, vaticinada por Hardin (1968), e, ainda, em modelos que demonstraram como o poder de fixar a agenda política, por meio da iniciativa ou da exclusividade na proposição de matérias, pode produzir efeitos centrípetos sobre o processo decisório (Tsebelis, 2002; Cox e McCubbins, 1993).

Contudo, parece possível identificar pelo menos dois conjuntos de questôes que desafiam o potencial da teoria institucionalista para oferecer um modelo adequado a explicar o efeito causal de instituições sobre processos e comportamentos políticos: [1] em primeiro lugar, a ausência de uma interpretação generalizante capaz de identificar quais e sob que condiçôes instituições são eficazes e, de fato, importam, explicando por que sob certos contextos instituições em curso não se mostram eficazes em resolver problemas de coordenação social, nem tampouco produzem os efeitos preditos pelo modelo ou suas versões; [2] paralelamente, o desafio consiste em endogeneizar a causalidade atribuída às instituições, explicando as condiçôes de origem e formação de estruturas políticas que irão, uma vez constituídas, condicionar as escolhas dos agentes e os resultados de conflitos políticos.

Poder-se-ia argumentar que um modelo de explicação institucional generalizante capaz de satisfazer a condição [1] é reconhecido na hipótese de Lijphart, sobre a associação entre arranjos power-sharing e estabilidade poliárquica. Decisôes compartilhadas e limites ao exercício de poder de maiorias seriam responsáveis pela constituição de um equilíbrio subótimo, no qual os agentes políticos não teriam interesse ou recursos para perseguir estratégias de mudança institucional. Problema adicional aqui diz respeito ao potencial para fixarem-se consequências unívocas atribuídas a modelos institucionais particulares. Isto pode ser visualizado ao recordarem-se as conclusões propostas por Lijphart (1996) acerca 
da estabilidade institucional da poliarquia na Índia. Procurando compreender por que, a despeito do obstáculo negativo constituído pelos níveis de desigualdade sociais e diferenças culturais na sociedade hindu, instituições poliárquicas apresentam continuidade por mais de cinco décadas, Lijphart sugere que o enigma pode ser decifrado pela dinâmica consociativa responsável por traduzir clivagens societárias em power-sharing. $\mathrm{O}$ paradoxo da interpretação de Lijphart aparece no fato de que efeitos consociativos são gerados por instituições majoritárias, como a regra eleitoral de maioria uninominal e a frequência em que o Partido do Congresso formou governos de maioria unipartidária. Em outras palavras, as consequências políticas provocadas pela configuração institucional são discrepantes em relação aos efeitos preditos, sendo necessário incorporar elementos exógenos ao modelo para explicá-los: a concentração territorial de minorias étnicas inibindo o impacto concentrador da competição majoritária uninominal, produzindo maior dispersão na distribuição de cadeiras legislativas. Combinado a isto, subdivisões de língua, casta e seitas dentro da maioria hindu incrementam custos de transação para sua coordenação, permitindo a grupos minoritários o exercício de um poder de veto que amplia direitos e limites sobre autoridades governamentais.

Para ser justo, é preciso reconhecer que o $p a-$ radigma majoritário (Melo, 2007) foi um esforço convergente para a definiçãao de um desenho institucional considerado apto a produzir incentivos para equilíbrios políticos. Regras que favoreçam a expressão ou a manufatura de maiorias governamentais, como fórmula eleitoral majoritária e seus efeitos na geração de maiorias unipartidárias e em coalizões minimamente vitoriosas e a limitação de veto-players com a neutralização de governos divididos, foram descritas como mecanismos causais para explicar a durabilidade e a consistência de experimentos democráticos bem-sucedidos. Em seu rastro, a configuração institucional adotada por poliarquias latino-americanas terminou por ser responsabilizada pelos ciclos de instabilidade política observados nestes casos: presidencialismo, federalismo e representação proporcional incrementariam os custos para a produção de maiorias, gerando impasses políticos.

Pode-se isolar o problema dos efeitos discrepantes produzidos por instituições políticas quando se reconstitui o debate desenrolado desde o início dos anos de 1990 acerca das perspectivas para a estabilidade dos novos regimes políticos poliárquicos (Przeworski, 1992; O’Donnell, 1992; Mainwaring, 1992; Mainwaring, O’Donnell e Valenzuela, 1992; Palermo, 2000, Carroll e Shugart, 2005). Grande parte das interpretaçóes foi orientada por uma matriz comum que atribuiu às instituiçôes políticas a condição para produzir estabilidade às novas poliarquias latino-americanas, variando, contudo, na identificação de quais instituiçõos seriam relevantes para induzir estratégias cooperativas de elites e partidos políticos. Neste ponto, pode-se localizar um descompasso entre o exercício de comparação como controle - refutação de hipóteses generalizantes - e um rarefeito conhecimento cumulativo sobre o tipo de configuração institucional capaz de induzir equilíbrios políticos.

Considerando o influente diagnóstico proposto por Linz (1990, 1991), o presidencialismo deveria produzir consequências perversas à estabilidade democrática, uma vez que ao separar a escolha eleitoral de presidente e Congresso provocaria (a) legitimidade dual; (b) rigidez institucional, associada ao mandato presidencial fixo, sem alternativas quando se esgota a popularidade governamental; (c) dinâmica do tipo soma-zero nas relações Executivo-Legislativo, na qual nem deputados possuiriam incentivos para colaborar com o governo, nem este disporia de recursos suficientemente elásticos para manter coalizóes de apoio parlamentar; e, por fim, (d) ausência de uma força moderadora capaz de intervir nos conflitos governo/Congresso. Como alternativa, governos parlamentaristas teriam a resposta institucional para gerar responsabilidade congressual, flexibilidade política, e acomodação em contextos de crise. Variante desse diagnóstico pode ser encontrado no argumento de Mainwaring e Shugart (1993), para quem não seria o presidencialismo, mas apenas sua versão de presidencialismo multipartidário, quando o número e a dispersão de partidos incrementariam o custo para a formação de coalizôes governamentais, que im- 
plicaria em aumento na probabilidade de impasse nas relações Executivo/Legislativo e instabilidade política. Neste caso, a configuração que importa não seria a separação de poderes como característica genética do presidencialismo, mas eleição presidencial com maioria simples, baixas magnitudes eleitorais e simultaneidade da disputa presidencial/ legislativa como fatores inibidores de instabilidade e crise política. Paralelamente, Shugart e Carey (1992) também sugeriram que a disjuntiva não estaria localizada entre formatos institucionais presidenciais versus parlamentares, como indicado por Linz, mas na configuração de poderes legislativos e não legislativos atribuídos a governos executivos. Estabilidade democrática seria mais provável sob combinação institucional baseada em limitados recursos decisórios presidenciais - maioria simples para a derrubada de veto presidencial e o recurso de legislar por decreto circunscrito a casos excepcionais e por tempo limitado - associados a fatores capazes de reduzir o custo para a formação de maiorias governamentais.

Examinados em retrospectiva, as três décadas percorridas desde a transição para um regime poliárquico revelaram um processo discrepante em relação ao que havia sido predito. Contrariando as previsões de que a combinação presidencialismo/ representação proporcional seria a fonte de curto-circuito institucional e crises políticas, resultados apresentados por Figueiredo e Limongi (1999, 2006) mostraram que isso ocorre por conta do controle governamental sobre o processo decisório congressual, associado à presença de coalizōes governamentais estáveis e previsíveis. A Constituição de 1988 teria conferido ao Executivo brasileiro mecanismos institucionais especialmente configurados em poder de agenda, que induziriam a colaboração do Congresso e assegurariam o fluxo de sua agenda decisória. Adicionalmente, dispositivos regimentais à disposição dos líderes partidários lhes conferem um poder elevado sobre a chance de êxito das iniciativas operadas por parlamentares individuais, terminando por assegurar aos líderes a capacidade de obter a adesão de suas bancadas para sua orientações de voto (Figueiredo e Limongi, 1999, p. 113). Assim, presidencialismo teria produzido equilíbrio, mas não pelos dispositivos apontados por Shugart e
Carey (poderes legislativos < poderes não legislativos), e sim por mecanismos que configuram poder de agenda ao Executivo. Instituições importam, mas quais instituiçōes importam?

Um segundo conjunto de hipóteses causais deslocou seu foco do sistema de governo para as regras que regulam a competição eleitoral e, sobretudo, o preenchimento de cadeiras partidárias, como fatores relevantes para explicar comportamento partidário estável e previsível e, em consequência, eficácia governativa.

A relação entre manutenção de carreira políti$\mathrm{ca}$, a busca de votos personalizados e mandatos legislativos orientados para a captura de recursos dirigidos para o reduto eleitoral, com consequências sob a forma de incremento nos custos de transação políticos (Mayhew, 1974; Cain, Ferejohn e Fiorina, 1987), inspiraram um conjunto de explicações causais para os dilemas de institucionalização partidária e (in)governabilidade na América Latina.

O trabalho de Scott Mainwaring (1991) foi pioneiro no emprego do modelo de electoral connection para interpretar a competição sob voto preferencial no Brasil. Conforme o autor, a introdução de listas abertas previamente à institucionalização de partidos nacionais teria gerado uma estrutura de incentivos responsáveis pela precária disciplina e lealdade de parlamentares em relação a dirigentes partidários. Não oferecendo aos dirigentes partidários a prerrogativa de confeccionar uma hierarquia prévia dos candidatos, e submetendo o sucesso eleitoral individual à conquista de sufrágios personalizados, como regra para o ordenamento de candidatos, este procedimento teria (i) reduzido custos eleitorais para a violação de lealdades partidárias e (ii) incentivado a competição intrapartidária, sob a forma de migração interpartidos, menor disciplina legislativa, reproduzindo uma situação endêmica de fragilidade partidária.

Carey e Shugart (1996) criaram um escore para medir o efeito provocado por diferentes fórmulas eleitorais na geração de reputação partidária ou pessoal como recurso para carreiras políticas. Para isso, consideraram os meios de controle à disposição da liderança partidária: prerrogativa das nominaçōes e ordenamento dos eleitos (ballot), transferência de votos (pool), restriçôes à compe- 
tição intrapartidária e a existência de barreiras à formação de novos partidos, promovida pela magnitude dos distritos eleitorais. Assim, lista aberta, candidatos natos e elevada magnitude das circunscriçôes eleitorais incrementariam o potencial de competição intrapartidária, reduzindo o controle da liderança partidária sobre candidatos e ampliando o valor de reputações pessoais como capital político. Como exemplos, as múltiplas listas partidárias com transferência limitada da Colômbia (até 2003) constituiriam regras com maiores incentivos para a captura de votos pessoais. Em um caso como o brasileiro, a transferência intrapartidária de votos nominais poderia ser um fator capaz de mitigar a personalização causada pelo voto personalizado. Contudo, de acordo com Carey e Shugart, distritos com maior magnitude eleitoral produziriam efeitos opostos, incrementando o valor de votos personalizados.

Estudos comparativos mostraram que quando controlado por desenvolvimento econômico e longevidade temporal de sistemas partidários nacionais, listas e magnitude eleitoral mostraram-se não significativas estatisticamente para explicar diferenças na institucionalização partidária e desempenho institucional. Fatores exógenos parecem necessários para dar conta do impacto de instituiçôes sobre comportamentos e estratégias. Assim, desenvolvimento econômico confirmou exercer influência sobre a fragmentação partidária e o incremento na participação eleitoral, paralelamente à robusta relação com accountability e transparência. A antiguidade temporal das organizaçôes partidárias mostrou-se um bom preditor sobre a estabilidade de eleitorados: quanto maior o tempo de vida médio dos partidos, menores as taxas de volatilidade eleitoral (Marenco dos Santos, 2006, 2010).

As dificuldades para isolar-se efeitos unívocos produzidos por modelos institucionais sobre o desempenho político ficam patentes quando se observam os resultados discrepantes encontrados na literatura acerca dos efeitos produzidos por diferentes escalas de magnitude eleitoral (Myerson, 1993). Conforme Kunicová e Rose-Ackerman (2005), fórmulas eleitorais de maioria uninominal simples (plurality) geram fortes incentivos ao monitoramento de incumbents em contraste com o maior custo de informação eleitoral em modelos de representação proporcional (RP) com lista aberta. Em direção convergente, para Carey (2009a e b), distritos com magnitudes elevadas ampliam custos de monitoramento, incentivando estratégias eleitorais de incumbents orientadas por rent-seeking. Paralelamente, Persson e Tabellini (2003) isolaram a associação inversa entre magnitude eleitoral $(\mathrm{M})$ e corrupção: quanto maior número de vagas em disputa nas circunscrições eleitorais, mais baixas as barreiras de entrada, incrementando a competição eleitoral, a informação disponível e o potencial de sanção, pelos eleitores. Por outro lado, Chang e Golden (2006) perceberam que magnitude eleitoral não provoca efeitos homogêneos: corrupção pode beneficiar-se de uma estrutura de oportunidades fixada seja por (i) voto preferencial com M elevado, quando o incremento no número de candidatos provoca aumento no custo de informação eleitoral e diminuição na probabilidade de punição por eleitores, como sob (ii) listas fechadas e $\mathrm{M}$ pequeno, combinando controle do ordenamento de candidatos concentrado pelas lideranças partidárias, com maior quociente relativo, menor número de partidos e candidatos e, como resultado, menor competição eleitoral.

A discrepância na identificação de quais instituições importam - presidencialismo, multipartidarismo, poderes legislativos e não legislativos, regras eleitorais, poder de decreto - revela que, para além da definição mais genérica e evidente de que instituições provocam efeitos sobre estratégias e interaçôes políticas, parece não haver uma teoria robusta apta a explicar quais instituições são capazes de provocar que tipo de efeitos, por que são eficazes, ou, inversamente, por que outras estruturas não geram os efeitos preditos. O resultado, na ausência de uma teoria compreensiva, são proposições nas quais a causalidade instituiçóes > resultados parece ser encontrada em combinaçôes ad hoc de regras e configurações institucionais específicas. $\mathrm{Ou}$, ainda, na redução de teorias, de paradigmas explicativos a meras abordagens, conforme os parâmetros apresentados por Geddes (2003, p. 21). 


\section{Muito controle, pouca explicação}

Recuperar uma vocação nomológica voltada para a construção de inferências causais com evidências e bases mais sólidas exige um acerto de contas com duas noções fortemente consolidadas na tradição dos estudos comparados: em primeiro lugar, a crença de que o método comparado caracteriza-se por muitas variáveis, poucos casos; em segundo, o uso quase automático de desenhos comparativos sincrônicos, a despeito dos limites e dos problemas que possam estar a eles associados.

Provavelmente, o artigo "Comparative politics and comparative method", publicado por Lijphart em 1971, influenciou toda uma geração de estudos comparados, consagrando a premissa de uma distinção entre método estatístico e comparado e a premissa que este último se caracteriza por um número pequeno de casos: "dada a inevitável escassez de tempo, energia e recursos financeiros, uma análise comparativa intensiva de poucos casos pode ser mais promissora do que uma análise estatística mais superficial de muitos casos" (Idem, p. 685). Não parece difícil reconhecer esta recomendação na seminal geração de estudos histórico-comparativos, como os trabalhos de Moore, Bendix, Skocpol, Tilly e Almond e Verba.

Em seu clássico As origens sociais da ditadura e da democracia, Barrington Moore ([1967] 1983) não precisou mais do que três casos para reconstruir as rotas então conhecidas para a modernidade democrática: Inglaterra, França e Estados Unidos. Theda Skocpol (1979) fixou-se na Rússia, na China e na França para dissecar as revoluções modernas. Com apenas cinco casos, Almond e Verba (1963) registraram as diferenças entre contextos impregnados por cultura cívica aqueles dominados por culturas paroquiais ou de sujeição.

Naquele momento, método comparado fora compreendido fortemente como modelo de estudos case-based, em oposição a investigações $v a$ riable-based, nos termos estabelecidos por Ragin e Zaret (1983). Trata-se de valorizar a dimensão histórico-comparativa de casos coletados e densamente reconstituídos em múltiplas variáveis.

Utilizando seja o método das concordâncias, quando se procura explicar semelhanças a partir da possibilidade de isolar um fator causal comum em meio a singularidades e discrepâncias entre os casos, seja o das diferenças (contrastes entre casos explicados pelas singularidades destacadas em meio às múltiplas semelhanças), a expectativa recai sobre a possibilidade de explicar-se padrões a partir de casos adequadamente escolhidos e comparados: por que Brasil e Argentina apresentam padróes de construção de Estados nacionais distintos? Como explicar um padrão de centralização estatal na experiência francesa em contraste com a tradição de statelessness anglo-saxâ? Que fatores ajudam a compreender a distância entre os modelos escandinavo, francês e norte-americano de welfare state? Por que a institucionalização poliárquica foi mais serena e estável na Inglaterra do que na Alemanha?

Podemos compreender muito da centralização estatal brasileira quando comparamos as trajetórias de construção nacional de Brasil e Argentina; podemos interpretar a extensão das políticas redistributivas escandinavas contrastando com a evolução das políticas públicas norte-americanas; ou, ainda, coletarmos elementos para compreender a estabilidade institucional de Cabo Verde quando comparamos sua história e estrutura social com a de um país tão próximo como Guiné-Bissau, mas de infortúnio institucional. Se nossa agenda resume-se a explicar o Brasil, a Suécia ou Cabo Verde, o modelo parece ser satisfatório. Mas isto significa que uma estratégia $c a-$ se-based é capaz de fornecer elementos de inferência causal para explicar a adoção de políticas keynesianas combinadas à expansão de gastos sociais, ou de identificar mecanismos causais para explicar o que as naçôes classificadas como free pela Freedom House têm que as diferenciam de países com baixos índices de liberdades civis e direitos políticos?

Quando Dahl, em uma genial intuição, percebe que a sequência virtuosa liberalização $=>$ democratização poderia ser irreplicável em novos e futuros casos de democratização, em contextos com histórias distintas daquelas das nações da Europa ocidental e da América do Norte, termina por chamar a atenção para a complexidade dos processos de democratização no que viria a ser chamada de a terceira onda, em decorrência do número e da heterogeneidade de nações a adotar modelos poliárquicos. A escala desse fenômeno pode ser capturada pela série temporal mostrada no gráfico a seguir, 


\section{Figura 1}

\section{Classificação de Regimes Políticos conforme Cheibub e Gandhi, 1945-2002}

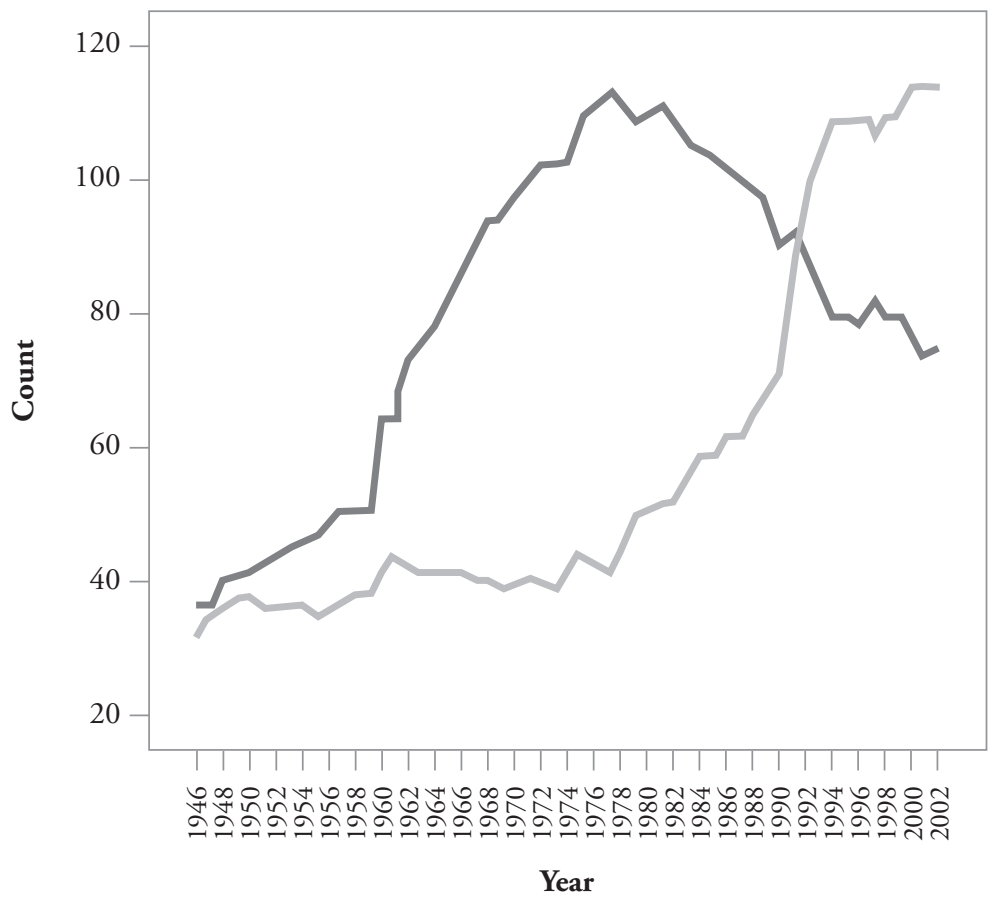

Cheibub type of regime

Democracy Dictatorship

Fonte: Norris (2008).

registrada pela classificação de regimes políticos fornecida por Cheibub e Gandhi.

Nações com regimes democráticos passaram de pouco mais de três dezenas -geográfica e culturalmente concentradas - em 1945, para mais de cem, na virada do milênio. Países com díspares registros democráticos, instituições, história, cultura, dimensão territorial, riqueza, taxas de desigualdade, diferenciação e complexidade na estrutura social, como África do Sul, Belize, Benin, Botswana, Brasil, Bulgária, Cabo Verde, Chile, Coreia do Sul, Estônia, Gana, Indonésia, Kiribaiti, Lesotho, Mongólia, Polônia, República Checa, Taiwan, Ucrânia, tornaram-se e mantiveram-se democráticos nas últimas duas décadas. Diante de tal diversidade, seríamos ainda capazes de responder à questão formulada em 1972 por Dahl ${ }^{1}$ - que definiu grande parte da agenda dos estudos institucionais comparados - apenas com um número pequeno de casos?

\section{A ordem dos fatores altera o produto?}

O apelo existente pelo uso de modelos baseados em recorte sincrônico pode ser verificado no inventário realizado por Pierson (2004, p. 98) em quatro dos principais periódicos comparativos editados nos Estados Unidos e que revelou que cerca de $50 \%$ dos trabalhos neles publicados apresentavam recorte analítico fundado em um desenho com horizontes temporais curtos.

A literatura institucionalista tem apresentado exemplos abundantes de como certas instituições, uma vez criadas, são capazes de produzir efeitos fortes, reconvertendo preferências e estratégias dos agentes políticos e, com isso, promovendo equilíbrios estáveis. Entretanto, uma causalidade robusta conferida às instituições deve ser capaz de enfrentar o desafio de explicar a origem delas, as condiçôes nas quais cada configuração institucional foi escolhida por elites políticas que irão sofrer, pos- 
teriormente, coerções exercidas pelas regras eleitas por elas próprias. Ao mesmo tempo, deve explicar a variação nos modelos institucionais, a continuidade, a estabilidade, a decadência e a mudança nas instituições políticas.

A constatação de que instituições produzem consequências relevantes para os conflitos políticos não autoriza que se as interprete como estruturas exógenas aos processos políticos ou, ainda, simples consequências provocadas pelo preenchimento de funçôes sociais latentes (resolução de problemas de ação coletiva, ou a indução ao desenvolvimento econômico, por exemplo). Considerando as condições de incerteza, informação incompleta e horizontes temporais que cercam as escolhas e as interações individuais, deve-se explicar como surgem as instituições que - ex-post - descobrimos serem capazes de resolver problemas de cooperação social. Mais ainda, explicar por que sob outras coordenadas instituições são ineficientes para promover cooperação e equilíbrios sociais.

Neste ponto, não se deve negligenciar as advertências de Pierson (2004) sobre os limites para o exercício do desenho institucional, ou as dificuldades para a fixação de um modelo universal de equilíbrio structure-induced: instituiçōes geram múltiplos efeitos, reformadores podem ter horizontes temporais curtos, instituições são produto de escolhas não antecipadas, "esclerose" dos atores em face da mudança contextual e, por fim, a descontinuidade dos atores. Isso implica em deslocar o foco da investigação, de uma teoria institucional para uma teoria de instituiçôes, tal como indicado por Diermeier e Krehbiel, cuja ênfase é "explicar por que algumas configurações institucionais são criadas e persistem, enquanto outras não existem ou são apenas transitórias" (2003, p. 130).

Para Pierson, três elementos incrementam as fontes de resiliência institucional: [1] veto-points, [2] custos de reversão de decisões políticas e [3] positive feedback. Se horizontes temporais são irrelevantes em relação aos efeitos de veto-points (retornos crescentes marginais gerados pelo tempo sobre quórum de decisões constitucionais), representam, inversamente, custos crescentes na resolução de problemas de coordenação visando à alternação do satus quo e incentivos para investimentos em estratégias condicionadas pelos parâmetros institucionais. Nesse sentido, as condições originais presentes na formação institucional e a sequência cronológica dos eventos são responsáveis pela geração de uma inércia estrutural. O tempo, aqui, apresenta efeito de retornos crescentes, ou positive feedback (Pierson, 2004, p. 18) reforçando com seu prolongamento a aderência institucional.

Calcanhar de Aquiles desta abordagem poderia residir em um determinismo derivado da aplicação do conceito de incremental returns: se o tempo gera retroalimentação positiva, e quanto maior longevidade temporal, maiores os custos de reversão institucional, como incorporar a ocorrência de mudança institucional ao modelo? Como compreender a inversão de padrão, representada pelo welfare state, em relação à longa tradição britânica de statelessness? (Badie, 1992).

Uma solução para esta cilada pode ser encontrada na indicação de Pierson (2004, p. 81) acerca de horizontes temporais relativos a fatores causais e a seus efeitos. Fenômenos físicos apresentam diferentes horizontes temporais em relação a causas geradoras e efeitos resultantes: curtos/curtos (tornados), curtos/longos (extinção causada por meteorito caído na Terra), longos/curtos (terremotos) e longos/longos (aquecimento global). Processos políticos path-dependent caracterizar-se-iam por uma combinação de fatores causais de curto prazo, com efeitos cumulativos de longa duração e altos custos de reversão - conjunturas críticas com alterações em preferências e estratégias dos agentes e impacto de fatores exógenos.

Mahoney e Thelen (2010) ofereceram novo aporte para a construção de um modelo explicativo ao problema da mudança institucional, considerando duas dimensōes: (i) contexto político, marcado por fortes ou fracos pontos de veto formais/informais; (ii) configuração institucional, segundo os graus de discricionariedade existentes na interpretação e cumprimento de regras. Fortes pontos de veto, combinados à baixa discricionariedade no cumprimento de regras, incentivariam agentes orientados para uma sobreposição de novas às antigas regras; pontos de veto com alta discricionariedade resultaria em agentes orientados 
por estratégia de alteração de regras e manutenção institucional; frágeis pontos de veto poderiam ocasionar tanto estratégias de deslocamento de regras e instituições (quando acompanhados por reduzidos graus de discricionariedade) como conversão e adaptação nestas.

O desafio neste ponto consiste em solucionar um aparente oximoro: como combinar (i) ampliação do número de casos, característica de modelagem variable-based, com (ii) incorporação da dimensão temporal, que emprega análises com número pequeno de casos e sob a forma de detalhadas narrativas históricas com a reconstituição de múltiplas variáveis, exercício aparentemente impraticável em grandes números de casos (Pierson e Skocpol, 2000; Mahoney, 2000)? A resolução desta equação pode ser viável incorporando a dimensão diacrônica com um processamento que reduza a dimensão temporal a variáveis comparáveis. Nessa perspectiva, intervalo temporal e sequências de processos ou eventos podem oferecer possibilidades de codificação temporal, permitindo comparações com muitos casos. Se tempo exerce efeitos do tipo incremental returns, ampliando custos para a reversão do status quo (incentivos para investimentos e coordenação por parte dos agentes, conforme Pierson), quanto mais instituiçôes prolongam sua existência, mais resilientes tornam-se. Isto pode ser medido ou testado considerando-se o tempo de vida de instituições, como regimes políticos, partidos, constituições. Paralelamente, a codificação de trajetórias ou sequências temporais em padrões informados por teorias positivas [competição $>$ inclusividade, civil $>$ político $>$ social] oferece a possibilidade de parangonar e simplificar processos complexos. Pode-se traçar uma correspondência entre modelos de comparação diacrônica e estratégias de investigação variable-based, orientadas por comparação de variações concomitantes do tipo "A B C ocorrem junto com x y z" ou "A + B C resulta em $x+y$ z", o que pode conferir significância a variáveis constituídas por sequências e intervalos temporais.

Assim, por exemplo, controlando a causalidade sincrônica produzida pelas Leis de Duverger, Sartori (1976) sugeriu que os efeitos redutores provocados por pluralidade uninominal deveriam ocorrer sob condiçôes nas quais sistemas partidários estruturados nacionalmente e configurados sob dispersão territorial do eleitorado em proporção abaixo da pluralidade estivessem previamente presentes na adoção desta regra. De modo simultâneo, a ordem dos fatores "institucionalização partidária/reforma eleitoral” teria sido relevante: em contextos marcados por sistema partidário forte antes da introdução da representação proporcional teria havido um bloqueio à oferta de novos competidores, inibindo a dispersão eleitoral atribuída ao proporcionalismo. Seguindo por esta trilha, pode-se chegar às conclusôes do trabalho seminal de Lipset e Rokkan (1993), indicando que sistemas partidários estruturados seriam o resultado de uma sequência temporal na qual a sedimentação de clivagens sociais, religiosas, culturais ou territoriais precede a inclusão do eleitorado promovida pela introdução do sufrágio universal masculino.

Em T. H. Marshall ([1963] 1967) e Reinhard Bendix ([1963] 1996), pode-se reconhecer um modelo sequencial de desenvolvimento, no qual a trajetória de expansão de direitos de cidadania civil-politico-social teria exercido efeitos relevantes no padrão de construção de Estado ocidental, em suas coordenadas de governo representativo e de liberdades individuais. Em contraste, Santos (1987) e Carvalho (1995) sugeriram que a ocorrência invertida desta ordem na experiência brasileira, com a promoção de direitos sociais precedendo a competição eleitoral e o exercício de direitos políticos através do voto, teria sido responsável por inibir a generalização de liberdades individuais e contribuir para um padrão de centralização estatal e atraso na produção de mecanismos de responsabilização de autoridades governamentais. Mais uma vez, a ordem dos fatores parece alterar o produto final.

Se isto estiver correto, deve-se ir além da comparação sincrônica, descrita por Bartolini (1994, p. 115) pelo emprego de um número médio de unidades espaciais, de média a grande quantidade de variáveis ou propriedades analisadas, sobre uma unidade singular de tempo. Nessa direção uma resposta ao problema da escolha, formação e estabilidade institucional está relacionada com 
os custos elevados para a reversão de políticas ou regras institucionais, presentes sob a forma de path-dependency (Hagopian, 1992). As condições originais presentes na formação institucional e a sequência cronológica dos eventos - indicando que neste caso a ordem temporal dos fatores altera o produto final - são responsáveis pela geração de uma inércia estrutural. $\mathrm{O}$ tempo, aqui, apresenta efeito de retornos crescentes, ou positive feedback (Pierson, 2004, p. 18), constrangendo, com seu prolongamento, a margem de mudança institucional: "com retornos crescentes, instituiçôes importam”, como sublinha North (1990, p. 95). A indicação de Pierson, de que processos de tipo path-dependent envolvem uma combinação de efeitos de longa duração (pelos elevados custos de reversão neles embutidos) com fatores causais fixados em recortes temporais curtos parece constituir uma sugestiva pista capaz de dispensar o determinismo e a irreversibilidade histórica.

Um exercício de comparação que considere os processos de institucionalização poliárquicos como path-dependent e incorpore sequências temporais como variável explicativa para a análise pode chegar a achados significativos na interpretação das diferenças institucionais em novas democracias latinoamericanas. Diferenças de duração e sequências envolvendo diferentes etapas de processos de transição democrática possuem efeitos sobre os resultados desses processos: (i) início da liberalização política, (ii) implantação de um governo civil, (iii) realização de eleiçôes competitivas para a presidência da República e (iv) onquista deste posto por político vinculado à oposição democrática. Intervalos mais extensos entre início de liberalização e a alternância de governo para uma oposição democrática podem explicar diferenças como as observadas na reabilitação de setores conservadores pró-regime - como veto- player e também na condição de coalizões eleitorais e de governo, no Brasil; em contraste com o ostracismo de seus correlatos argentinos e uruguaios ou a exclusão aos postos governamentais nacionais imposta à direita chilena desde 1990 e 2010, pela coalizão de centro-esquerda (Marenco dos Santos, 2008).

\section{Conclusão}

Quando queremos isolar elementos singulares de fenômenos ou casos políticos específicos, estratégias comparativas do tipo case-based podem constituir recurso útil e promissor para a identificação de fatores que, de outro modo (em estudos de caso, por exemplo), não perceberíamos como peculiares, ou, inversamente, na ausência de controle seríamos tentados a atribuir selo de originalidade a eventos comuns a processos similares. Ao comparar as trajetórias históricas de Inglaterra e França, Tocqueville ([1835] 1987) pôde captar elementos para interpretar a tradição liberal anglo-saxã, em oposição ao republicanismo igualitário francês. Pode-se também proceder a "comparaçôes implícitas”, como sugere Sartori (1994, p. 32), tomando modelos teóricos generalizantes e controlando-os à luz de casos particulares, sem que, necessariamente, se lance mão de um desenho com $n>1$. A refutação das teorias sobre a associação entre presidencialismo e ingovernabilidade, para o caso brasileiro, pode ilustrar o uso desta estratégia.

O problema consiste em que comparações case-based ou, ainda, implícitas, embora úteis para identificar singularidades ou falsificar teorias, deixa como legado uma coleção de achados não cumulativos e um vácuo de saber nomológico. $\mathrm{O}$ resultado parece ser um estado da arte marcado por muitas perguntas e poucas respostas acerca de uma das indagações centrais da agenda de estudos comparados: quais instituiçôes, realmente, importam?

Se quisermos construir teorias de médio alcance aptas a responder interrogaçōes como causas para a variação institucional, equilíbrios sociais e ação coletiva, a exigência recairá sobre desenhos de investigação comparativa que permitam obter resultados mais robustos. Dada a complexidade e a heterogeneidade de casos (nacionais), parece improvável capturar a diversidade de processos utilizando conjuntos com poucos casos, como a experiência do passado permitiu às gerações fundadoras dos estudos comparados. Por fim, este artigo buscou uma pista constituída pela possibilidade de a incorporação de sequências temporais em comparações diacrônicas oferecer maior robustez à construção de teorias explicativas. Neste caso, contrariando a premissa aritmética, a ordem dos fatores altera o produto final. 


\section{Notas}

1 "Dado um regime em que os opositores do governo não possam se organizar aberta e legalmente em partidos políticos para fazer-lhes oposição em eleições livres e idôneas, que condições favorecem ou impedem sua transformação num regime no qual isto seja possível?" (Dahl, [1972] 1997).

\section{BIBLIOGRAFIA}

ALMOND, Gabriel \& VERBA, Sidney. (1963), The civic culture: political attitudes and democracy in five nations. Princeton, Princeton University Press.

ARROW, Kenneth. (1951), Social choice and individual values. New Haven, Yale University.

BARTOLINI, Stefano. (1994), "Tiempo y investigación comparativa", in Giovanni Sartori e Leonardo Morlino, La comparación en las ciências sociales, Madri, Alianza.

BADIE, Bertrand. (1992), "Analyse comparative et sociologie historique". Revue Internationale des Sciences Sociales, 133: 363-372.

BENDIX, Reinhard. ([1963] 1996), Construção nacional e cidadania. São Paulo, Edusp.

BOIX, Carles \& STOKES, Susan. (2007), The Oxford handbook of comparative politics. Oxford, Oxford University Press.

CAIN, Bruce; FEREJOHN, John \& FIORINA, Morris. (1987), The personal vote: constituency service and electoral independence. Cambridge, Harvard University Press.

CAREY, John. (2009a), Legislative voting and accountability. Cambridge, Cambridge University Press.

(2009b). "Ingeniería electoral: qué nos muestran las investigaciones académicas sobre los efectos anticipados de las reformas electorales?", in A. Fontaine; C. Larroulet; J. Navarrete e I. Walker (orgs.), Reforma del sistema electoral chileno. $1^{\circ}$ edição, Santiago, PNUD.

CAREY, John \& SHUGART, Matthew. (1996), "Incentives to cultivate a personal vote: a rank ordering of electoral formulas". Electoral Studies, 13 (4): 417-439.
CARROLL, Royce Carroll \& SHUGART, Matthew. (2005), "Neo-Madisonian theories of Latin American institutions". Center for the Study of Democracy, University of California, Irvine, paper 05-01.

CARVALHO, José Murilo. (1995), Desenvolvimiento de la ciudadania en Brasil. México, Fondo de Cultura Económica.

CAVAROZZI, Marcelo \& GARRETÓN, Manuel. (1989), Muerte y resurrección: los partidos politicos en América Latina y las transiciones en el Cono Sur. Santiago do Chile, Flacso.

CHANG, Eric \& GOLDEN, Miriam. (2006), "Electoral systems, district magnitude and corruption”. British Journal of Political Science, 37: 115-137.

COLLIER, David. (1982), O novo autoritarismo na América Latina. Rio de Janeiro, Paz e Terra.

COLLIER, David \& COLLIER, Ruth. (1991), Shaping the political arena: critical junctures, the labor movement, and regime dynamics in Latin America. Princeton, Princeton University Press.

COX, Gary. (1997), Making votes count: strategic coordination in the world's electoral systems. Cambridge, Cambridge University Press.

COX, Gary \& McCUBBINS, Matthew. (1993), Legislative Leviathan: party government in the house. Berkeley, University of California Press.

DAHL, Robert. (1997), Poliarquia. São Paulo, Edusp.

DIERMEIER, Daniel \& Krehbiel, Keith. (2003), "Institutionalism as a methodology". Journal of Theoretical Politics, 15 (2): 123-144.

DUVERGER, Maurice. (1954), Os partidos politicos. Brasília, Editora da UnB.

(1986), "Duverger's law: forty years later", in Bernard Grofman e Arend Lijphart, Electoral laws and their political consequences, Nova York, Agathon.

FIGUEIREDO, Argelina \& LIMONGI, Fernando. (1999), Executivo e legislativo na nova ordem constitucional. São Paulo, FGV.

(2006). "Poder de agenda na democracia brasileira: desempenho do governo no presidencialismo multipartidário", in Gláucio Dillon Soares e Lúcio Rennó, Reforma politica: liçôes da história recente, Rio de Janeiro, FGV. 
GEDDES, Barbara. (2001), "O que sabemos sobre democratização depois de vinte anos?” Opinião Pública, 7 (2): 221-252. . (2003), Paradigms and sand castles: theory building and research design in comparative poltics. Ann Arbor, The University of Michigan Press.

GOODIN, Robert. (2009), "The State of the discipline, the discipline of the State", in (ed.), Oxford handbook of political science, Oxford, Oxford University Press, pp. 3-57.

HAGOPIAN, Frances. (1992), "The compromised consolidation: the political class in the brazilian transition", in S. Mainwaring, G. O'Donnell e J. S. Valenzuela (eds.), Issues in democratic consolidation: the new South American democracies in comparative perspective, South Bend, University of Notre Dame Press.

HARDIN, Garrett. (1968), "The tragedy of the Commons”. Science, 162: 1243-1248.

KUNICOVÁ, Jana \& ROSE-ACKERMAN, Susan. (2005), "Electoral rules and constitutional structures as constraints on corruption". British Journal of Political Science, 35: 295-330.

LIJPHART, Arend. (1971), "Comparative politics and comparative method". American Political Science Review, LXV: 682-693.

. (1990), "The political consequences of electoral laws, 1945-85". American Political Science Review, 84 (2): 481-497.

. (1996), "The puzzle of Indian democracy: a consociational interpretation". American Political Science Review, 90 (2): 258-268.

. (1999), Patterns of democracy: government, forms and performance in thirty-six countries. New Haven, Yale University Press.

LINZ, Juan J. (1990) "The perils of presidentialism”. Journal of Democracy, 1 (1): 51-69.

(1991), "Presidencialismo ou parlamentarismo: faz alguma diferença?", in B. Lamounier, J. Linz, A. Lijphart e A. Valenzuela, $A$ opção parlamentarista, São Paulo, Idesp/Sumaré.

LINZ, Juan J. \& STEPAN, Alfred. (1999), A transição e consolidação da democracia: a experiência do sul da Europa e da América do Sul. São Paulo, Paz e Terra.
LIPSET, Seymour \& ROKKAN, Stein. (1993), "Estruturas de clivagem, sistemas partidários e alinhamentos dos eleitores", in S. M. Lipset (ed.), Consenso e Conflito, Lisboa, Gradiva, pp. 161-259.

MAHONEY, James. (2000), "Strategies of causal inference in small-N analysis". Sociological Methods Research, 28/4: 387-424.

MAHONEY, James \& THELEN, Kathleen. (2010), "A theory of gradual institutional change", in , Explaining institutional change: ambiguity, agency, and power, Cambridge, Cambridge University Press.

MAINWARING, Scott. (1991), "Políticos, partidos e sistemas eleitorais: o Brasil numa perspectiva comparada”. Novos Estudos Cebrap, 29: 34-58.

(1992), "Transitions to democracy and democratic consolidation: theoretical and comparative issues", in S. Mainwaring, G. O'Donnell e J. S. Valenzuela (eds.), Issues in democratic consolidation: the new South American democracies in comparative perspective, South Bend, University of Notre Dame Press. . (1999), Rethinking party systems in the third wave of democratization: the case of Brazil. Palo Alto, Stanford University Press.

MAINWARING, S.; O'DONNELL, G. \& VALENZUELA, J. Samuel (eds.). (1992), Issues in democratic consolidation: the new South American democracies in comparative perspective, South Bend, University of Notre Dame Press.

MAINWARING, Scott \& SHUGART, Matthew. (1993), "Juan Linz, presidencialismo e democracia: uma avaliação crítica”. Novos Estudos Cebrap, 37: 191-213.

MAINWARING, S. e ZOCO, E. (2006), "Political sequences and the stabilization of interparty competition: electoral volatility in old and new democracies". Party Politics, 13 (2): 155-178.

MARCH, James \& OLSEN, Johan. (1989), Redescovering institutions: the organizational basis of politics. Nova York, Free Press.

MARENCO DOS SANTOS, André. (2006), "Regras eleitorais importam? Modelos de listas eleitorais e seus efeitos sobre a competição partidária e o desempenho institucional". Dados, 49 (4): 721-749. 
(2008), "Despacio se llega lejos? La transición para la democracia en el Brasil en perspectiva comparada”, in M. Alcántara Sáez e C. Ranulfo Melo (orgs.), La democracia brasileña: balance y perspectivas para el siglo XXI, Salamanca, Ediciones Universidad Salamanca. (2010). "Quando leis não produzem os resultados esperados: financiamento eleitoral em perspectiva comparada". Dados, 53: 821-853.

MARSHALL, T. H. ([1963] 1967), Cidadania, classe social e status. Rio de Janeiro, Zahar.

MAYHEW, David R. (1974). Congress: the electoral connection. New Haven, Yale University Press.

MELO, Marcus. (2007). "O viés majoritário na política comparada: responsabilização, desenho institucional e qualidade democrática”. Revista Brasileira de Ciências Sociais, 22 (63): 11-29.

MOORE JR., Barrington. ([1967] 1983), As origens sociais da ditadura e da democracia. São Paulo, Martins Fontes.

MYERSON, Roger. (1993), "Effectiveness of electoral systems for reducing government corruption: a game theoretic analysis". Games and Economic Behavior, 5, 118-132.

NOHLEN, Dieter \& THIBAUT, Bernhard. (1994), "Investigación sobre la transición en América Latina: enfoques, conceptos, tesis". Universität Heidelberg, Arbeitspapier, 11.

NORRIS, Pippa. (2008), Driving democracy: do power-sharing institutions work? Cambridge, Cambridge University Press.

NORTH, Douglass. (1990), Institutions, institutional change and economic performance. Cambridge, Cambridge University Press.

O’DONNELL, Guillermo. (1986), “O estudo de processo de democratização política a partir do Estado burocrático-autoritário", in , Contrapontos: autoritarismo e democratização, São Paulo, Vértice.

. (1992), "Transitions, continuities and paradoxes”, in S. Mainwaring, G. O'Donnell e J. S. Valenzuela (eds.), Issues in democratic consolidation: the new South American democracies in comparative perspective, South Bend, University of Notre Dame Press.
O’DONNELL, Guillermo \& SCHMITTER, Philippe. (1988), Transições dos regimes autoritários: primeiras conclusões, São Paulo, Vértice.

O'DONNELL, G.; SCHMITTER, P. \& WHITEHEAD, L. (1988), Transiçôes dos regimes autoritários: América Latina. São Paulo, Vértice.

OSTROM, Elinor. (1990), Governing the commons: he evolution of institutions for collective action. Cambridge, Cambridge University Press. . (1999), "Coping with tragedies of commons". Annual Review of Political Science, 2: 493-535.

PALERMO, Vicente. (2000), "Como se governa o Brasil? O debate sobre instituições políticas e gestão de governo”. Dados, 43 (3): 521-557.

PANEBIANCO, Angelo. (1994), "Comparación y explicación”, in Giovanni Sartori e Leonardo Morlino, La comparación en las ciências sociales, Madri, Alianza.

PERSSON, Torsten \& TABELLINI, Guido. (2003), The economic effects of constitutions. Boston, MIT Press.

PENNINGS, Paul; KEMAN, Hans \& KLEINNIJENHUIS, Jan. (2006), Doing research in comparative politics. And introduction to comparative methods and statistics. 2. ed. Londres, Sage.

PETERS, B. Guy. (1999), Institutional theory in political science: the new institutionalism. Cassel, Continuum.

PIERSON, Paul. (2004), Politics in time: history, institutions and social analysis. Princeton, Princeton University Press.

PIERSON, Paul \& SKOCPOL, Theda. (2000), "Historical institutionalism in contemporary political science”, in I. Katznelson e H. Milner (eds.), Political science: the state of the discipline, Nova York, Norton, 2002, pp. 693-721.

PRZEWORSKI, Adam. (1987), "Methods of cross national research, 1970-1983: an overview", in H. N. Dierkes e A. Berthoin Antal (orgs.), Comparative policy research: learning from experience. Londres, Gower Publishing.

(1992), "A escolha de instituiçôes na transição para a democracia: uma abordagem da teoria dos jogos”. Dados, 35 (1): 5-48.

RAE, Douglas. (1967), The political consequences of electoral laws. New Haven, Yale University Press. 
RAGIN, C. \& ZARET, D. (1983), "Theory and method in sociological research: two strategies". Social Forces, 61 (3): 731-754.

RAGIN, Charles. (1987), The comparative method: moving beyond qualitative and quantitative strategies. Berkeley/Los Angeles, University of California Press.

RIKER, William. (1962), The theory of political coalitions. New Haven, Yale University Press.

ROTHSTEIN, Bo \& Steinmo, S. (2002), "Restructuring politics: Institutional analysis and the challenges of modern welfare states", in (eds.), Restructuring the Welfare State: political institutions and policy change, Nova York, Palgrave, Macmillan.

SANTOS, Wanderley Guilherme. (1987), Cidadania e justiça. Rio de Janeiro, Campus.

SARTORI, Giovanni. (1976), Parties and party systems. Cambridge, Cambridge University Press. - (1994), "Comparación y método comparativo", in G. Sartori e L. Morlino, La comparación en las ciências sociales, Madri, Alianza.

- (1996), Engenharia constitucional: como mudam as constituiçôes. Brasília, Editora da UnB.

SHARE, Donald \& MAINWARING, Scott. (1986), "Transição pela transação: democratização no Brasil e na Espanha”. Dados, 29 (2): 207-236.

SHUGART, Matthew \& CAREY, John. (1992), Presidents and assemblies: constitutional design and electoral dynamics. Cambridge, Cambridge University Press.

SKOCPOL, Theda. (1979). States and social revolutions: a comparative analysis of France, Russia, and China. Cambridge, Cambridge University Press.

TAAGEPERA, Rein. (1984), "The efect of district magnitude and proprieties of two-seat districts", in A. Lijphart e B. Gorfman, Choosing an electoral system, Npva York, Praeger.

TAAGEPERA, R. \& SHUGART, M. (1989), Seats and votes: the effects and determinants of electoral systems. New Heaven, Yale University Press.

TILLY, Charles. (1991), Grandes estructuras, procesos amplios, comparaciones enormes. Madri, Alianza.
TOCQUEVILLE, Alexis. ([1835] 1987). La democracia en América. México, Fondo de Cultura Económica.

TSEBELIS, George. (2002), Veto players: how political institutions work. Princeton, NJ, Princeton University Press.

WEIR, M. \& SKOCPOL, T. (1985), "State structures and the possibilities for 'keynesian' responses to the great depression in Sweden, Britain and the United States", in P. Evans, D. Rueschemeyer e T. Skocpol, Bringing the State back in: new perspectives on the State as institution and social actor, Cambridge, Cambridge University Press. 


\section{QUANDO COMPARAMOS PARA EXPLICAR: DESENHOS DE PESQUISA E SEQUÊNCIAS TEMPORAIS NA INVESTIGAÇÃO DE INSTITUIÇŌES POLÍTICAS}

\section{André Marenco dos Santos}

Palavras-chave: Política comparada; Instituições políticas; Dependência de trajetória; Explicação.

Este artigo pretende mostrar que estudos comparados devem ser orientados para a construção de inferências causais generalizantes, aptas a explicar formação, estabilidade e mudança em instituições políticas. Partindo de uma identificação de impasses na teoria institucional, o texto procura mostrar a maneira pela qual a noção de comparação como estratégia investigativa baseada em poucos casos, muitas variáveis, terminou por reduzir seu potencial para a construção de explicaçôes generalizantes, limitando-a a um escopo de controle de hipóteses. Por fim, procuramos reforçar argumentos em favor da incorporação de intervalos e sequências temporais à análise comparada.

\section{WHEN COMPARING TO EXPLAIN: DESIGNS OF RESEARCH AND TEMPORAL SEQUENCES IN THE INVESTIGATION ON POLITICAL INSTITUTIONS}

\section{André Marenco dos Santos}

Keywords: Comparative politics; Political institutions; Temporal sequences; Path-dependence.

The argument of this paper is that the vocation of comparative studies is the search for generalizing causal inferences able to explain the formation, stability and change in political institutions. Initially, we tried to identify dilemmas in the institutional theory, located in the fragility of interpretations on institutions formation, as well as for the understanding of the conditions under which institutions appear to be able to cause the effects attributed to them; in the second section, we seek to show how the notion of comparison as a research strategy based on few cases, many variables, eventually reduces the potential for the construction of generalizing explanations. Finally, we sought to strengthen arguments for the incorporation of temporal intervals and sequences for comparative analysis.
QUAND ON COMPARE POUR EXPLIQUER: DESSINS DE

RECHERCHE ET SÉQUENCES TEMPORELLES DANS L'INVESTIGATION DES INSTITUTIONS POLITIQUES

André Marenco dos Santos

Mots-clés: Politique comparée; Institutions politiques; Dépendance de trajectoire; Explication.

Cet article a pour but de montrer que les études comparées doivent être orientées vers la construction d'inférences causales de généralisation, capables d'expliquer la formation, la stabilité et le changement dans les institutions politiques. En partant d'une identification d'impasses dans la théorie institutionnelle, le texte tente de démontrer la façon par laquelle la notion de comparaison en tant que stratégie investigatrice basée sur peu de cas, plusieurs variables réduit son potentiel de construction d'une explication de généralisation, en la limitant à un but de contrôle d'hypothèses. Pour conclure, nous tentons de renforcer les arguments en faveur de l'incorporation d'intervalles et de séquences temporelles à l'analyse comparée. 